\title{
Exposure to Citral, Cinnamon and Ruda Disrupts the Life Cycle of a Vector of Chagas Disease
}

\author{
${ }^{1}$ Charles I. Abramson, ${ }^{2}$ Elis Aldana and ${ }^{2}$ Enrique Sulbaran \\ ${ }^{1}$ Oklahoma State University, Laboratory of Comparative Psychology and Behavioral Biology \\ Departments of Psychology and Zoology, 215 N. Murray Stillwater, OK 74078, USA \\ ${ }^{2}$ Universidad de Los Andes, Departamento de Biologia, Laboratorio de Entomologia "Herman Lent" \\ Facultad de Ciencias, Nucleo La Hechicera, 5101 Merida, Venezuela
}

\begin{abstract}
The main vector of Chagas disease in Venezuela was exposed to the odors of citral, cinnamon and ruda. Cinnamon was found to stop the life cycle of Rhodnius prolixus relative to untreated animals. Citral and ruda also influenced the life cycle but not to the extent of animals exposed to cinnamon. We suggest that future research be directed toward using cinnamon in field and toxicity tests.
\end{abstract}

Key words: Ruta gaveolens toxicity, life cycle, molt, cinnamon toxicity, citral toxicity

\section{INTRODUCTION}

In the course of conducting experiments on the learning of Chagas disease vectors we discovered that exposure to cinnamon odor completely stops the life cycle of the triatomine Rhodnius prolixus by inhibiting the fifth-instar from turning into an adult ${ }^{[1-3]}$. The inability to molt into an adult prevents further reproduction and therefore the spread of Chagas disease. Exposure to the odor of citral and ruda (Ruta graveolens) delays the life cycle and is less effective than cinnamon relative to untreated animals.

Chagas disease is transmitted by triatomines and is endemic in rural areas. Chagas disease is the $4^{\text {th }}$ leading cause of death in Latin America and infects 16 to 18 million people with 100 million more at risk $^{[4]}$. Triatomines are haematophagous insects and transmission of the parasite takes place during and/or after engorgement when feces contaminate the skin.

There are no current vaccines against Chagas and there are no cures once the disease has progressed to the chronic phase. The lack of a vaccine and cure makes it imperative that greater effort be made to find stimuli that can serve as repellents. We believe we found one in cinnamon.

$R$. prolixus is the main vector in Venezuela and is a domestic species that adapts well to human dwellings, especially to houses with palm-thatched roofs ${ }^{[5]}$. The current method of control in Venezuela is the use of insecticides. The use of insecticides such as pyrethroids, organochlorides, organophosphates and carbamates is problematic because it leads to resistance, is often misapplied in rural areas and kills non-target organisms ${ }^{[6-9]}$. There is a need to find alternatives that can be used as part of an overall strategy of integrated pest management.

\section{MATERIALS AND METHODS}

Four groups of $R$. prolixus were maintained at $28 \pm$ $2^{\circ} \mathrm{C}$ and $50-60 \%$ relative humidity and reared from a laboratory colony started 30 years ago. The colony has never been exposed to insecticides nor have they been in contact with triatomines from the field. After molting from fourth-instar, the animals were starved and used within 7 days. Control animals $(n=30)$ were not exposed to any odor. Those in the remaining groups were exposed either to citral (Aldrich-Sigma Chemical, St. Louis, MO $n=50$ ), ruda (Perfumeria Vitel S.R.L., $n$ = 47) or cinnamon (Gilberties Herbs, Easton, CT, $n=$ 48). Although the main focus of our study was an investigation of cinnamon, ruda is known to disrupt feeding behavior in butterfly larvae (Hypsipyla grandella) and citral is known to be a repellent against mosquitoes (Aedes aegypti), house flies (Musca domestica) and cockroaches (Periplaneta americana $)^{[10-11]}$; we wanted to obtain data on whether similar effects can be observed in triatomines.

Each group was placed in a $500 \mu \mathrm{L}$ jar for the duration of the experiment. The lid consisted of a net to facilitate feeding. The odor was placed inside the jar by impregnating a cotton swab in $2.7 \mu \mathrm{L}$ of the odorant. The swab was left inside the jar containing the triatomines and replaced every two days. To induce the animals to molt, the jars containing triatomines were attached to a chicken for feeding once a week for the first 3 weeks of the experiment. The experiment lasted 71 days.

Correponding Author: $\quad$ E. Aldana, Departamento de Biologia Facultad de Ciencias, Universidad de Los Andes Nucleo La Hechicera 5101 Merida, Venezuela, Tel: 58274 240-1312, Fax: 58274 240-1286 
Am. J. Environ. Sci. 3 (1): 7-8, 2007

Table 1: The number of Rhodnius prolixus surviving and molting over 71 days exposed to three different odors

\begin{tabular}{|c|c|c|c|c|c|c|}
\hline \multirow[b]{2}{*}{ Day } & \multicolumn{3}{|c|}{ Number surviving } & \multicolumn{3}{|c|}{ Number molting } \\
\hline & Ruda & Citral & Cinnamon & Ruda & Citral & Cinnamon \\
\hline 0 & 47 & 50 & 48 & 0 & 0 & 0 \\
\hline 57 & 46 & 45 & 20 & 0 & 1 & 0 \\
\hline 63 & 22 & 7 & 16 & 24 & 34 & 0 \\
\hline 65 & 16 & 5 & 16 & 2 & 0 & 0 \\
\hline 71 & 16 & 5 & 15 & 0 & 0 & 0 \\
\hline
\end{tabular}

\section{RESULTS AND DISCUSSION}

The results of the experiment are quite striking and shown in Table 1. The number of animals surviving on examination days differed among the three odor treatment groups $\left(\chi_{8}^{2}=27.75, P<0.001\right.$, Power $=$ 0.986). Animals exposed to ruda and citral delayed molt onset relative to controls. All controls animals molted from the fith instar to adults before day 30 (98.2\%). Ruda and citral groups did not differ in the number of instars molting (Rank-sum test: $T=27.5, N=5, P=$ 0.916). None of the animals exposed to the odor of cinnamon molted from fifth-instar to adult. Exposure to cinnamon prevented the animals from feeding; therefore, they did not molt. The inability of cinnamon treated animals to feed during the first three weeks stimulated us to give them two more feeding opportunities. Again, they did not feed.

Our results are the first to demonstrate that exposure to the odor of cinnamon stops $R$. prolixus from molting into an adult and influences survival. Results of larvicidal tests have demonstrated that cinnamaldehyde and cinnamaldehyde/cinnamyl acetate type chemicals affected fourth-instar mosquito larvae $A$. aegypti $^{[12]}$. Our data are also the first to show that exposure to ruda and citral delay the onset of molting. Venezuela has excellent conditions to rear cinnamon trees and we suggest that future research be directed toward field tests and toxicity tests under laboratory conditions $^{[13]}$.

\section{ACKNOWLEDGMENTS}

This research was partially supported by CDCHTULA C-1341 Psicologia del aprendizaje: un nuevo enfoque para el estudio del comportamiento de triatominos en condiciones de laboratorio.

\section{REFERENCES}

1. Abramson, C.I., E., Aldana, E. Sulbaran-Romero and E. Lizano, 2006. Fifth instar experience influences attractiveness of the plant extrace Ruda (Ruta graveolens) in the triatomine Rhodnius prolixus Stal 1859. J. Vector Ecol., 31: 1-2.

2. Abramson, C.I., E. Sulbaran-Romero, J. Frasca, R. Fehr, E. Lizano and E. Aldana, 2005. Psychology of learning: A new approach to study behavior of
Rhodnius Prolixus Stal under laboratory conditions. Psych. Rep., 97: 721-731.

3. Aldana, E., F. Otalora, F. and C.I. Abramson, 2005. A new apparatus to study behavior of triatomines under laboratory conditions. Psych. Rep., 96: 825-832.

4. World Health Organization (WHO), 1991. Control of Chagas disease: Report of a WHO Expert Committee, WHO Tech. Rep. Ser. 811.

5. Gomez-Nunez, J.C. and J. Fernandez, 1963. La colonia de Rhodnius prolixus en el Instituto Venezolano de Investigaciones Cienificas. Bol. Dir. Malariol. San. Amb., 3: 132-137.

6. González-Valdivieso, F., D. Sanchez and F. Nocerino, 1971. Susceptibility of $R$. prolixus to chlorinated hydrocarbon insecticides in Venezuela. Unpublished document, WHO/VBC/71. 264.

7. Cockbum, J., 1972. Laboratory investigations bearing on insecticide resistance in triatomine bugs. Unpublished document, WHO/72.359.

8. Nocerino, F., 1976. Susceptibilidad de Rhodnius prolixus y Triatoma maculata a los insecticidas en Venezuela. Bol. Dir. Malariol. San. Amb., 16: 276283.

9. Vassena, C., M. Picollo and E. Zerba, 2000. Insecticide resistance in Brazilian Triatoma infectans and Venezuelan Rhodnius prolixus. Med. Veterin. Entomol., 14: 51-55.

10. Mancebo, F., L. Hilje, G. Mora, V. Castro and R. Salazar, 2001. Biological activity of Ruta chalepensis (Rutaceae) and Sechium pitteri (Cucurbitaceae) extracts on Hypsipyla grandella (Lepidoptera: Pyralidae) larvae. Rev. Biol. Trop., 49: 501-508.

11. Vartak, P.H., V.B. Tungikar and R.N. Sharma, 1994. Comparative repellent properties of certain chemicals against mosquitoes, house flies and cockroaches using modified techniques. J. Comm. Dis., 26: 156-160.

12. Sen-Sung, C., L. Ju-Yun, T. Kun-Hsien, C., WeiJune and C. Shang-Tzen, 2004. Chemical composition an mosquito larvicidal activity of essential oils from leaves of different cinnamomum osmophoeum provenances. J. Agric. Food Chem., 52: 4395-4400.

13. Leal, F., 1997. Especias: cultivos promisorios para Venezuela. Rev. Fac. Agron. (Maracay)., 23: 125-148. 